\title{
Higher education transformation in Indonesia during COVID-19 pandemic: implementation in Mulawarman University
}

\author{
Masjaya $^{1}$, Mustofa Agung Sardjono ${ }^{2}$, Swandari Paramita ${ }^{3}$, Anton Rahmadi ${ }^{*}$ \\ ${ }^{1}$ Faculty of Social and Political Sciences, Mulawarman University \\ ${ }^{2}$ Faculty of Forestry, Mulawarman University \\ ${ }^{3}$ Faculty of Medicine, Mulawarman University \\ ${ }^{4}$ Faculty of Agriculture, Mulawarman University \\ Corresponding Author: arahmadi@unmul.ac.id
}

\begin{abstract}
Coronavirus Disease 2019 (COVID-19) has hit the whole world, and the Indonesian government has firmly issued a disaster emergency status in mid-March 2020. All sectors of the economy, social, politics, security, and education suffer the COVID-19 pandemic impact. Higher education is one of the sectors that has suffered quite a severe impact. Mulawarman University, as a part of higher education, certainly does not remain silent in responding to this pandemic. Anticipatory actions that have been taken by Mulawarman University. The transformation of Mulawarman University academic activities consists of: (A) Lecture/teaching activities, (B) Practice activities (laboratory and fieldwork practices), (C) Learning evaluation activities (mid and final semester exam), (D) Final project guidance activities, (E) Research and community service activities, (F) Other (related) academic activities, (G) National/international events and professional/service trips at home/abroad, (H) New student admissions activities year of 2020 (SNMPTN; SBMPTN; and SMMPTN), and (I) Student activities/student work units. In conclusion, the academic transformation taken by Mulawarman University in responding to the COVID-19 pandemic is massive and comprehensive regarding all aspects of higher education.
\end{abstract}

Keywords: higher education, transformation, COVID-19 


\section{Introduction}

Coronavirus Disease 2019 (COVID-19) is a disease caused by a viral infection called Severe Acute Respiratory Syndrome Coronavirus 2 (SARS-CoV-2) (1). This disease has hit the whole world, and as of 31 August 2020, it has infected more than 25 million world population with deaths reaching 800,000 people (2). The Indonesian government has firmly issued a disaster emergency status in mid-March 2020, followed by government regulation concerning large-scale civil restrictions (3).

Of course, all sectors of the economy, social, politics, security, and education suffer the COVID-19 pandemic impact. Higher education is one of the sectors that has suffered quite a severe impact, namely the temporary suspension of activities that involve gathering large numbers of people or field activities due to social restrictions (4). The main activities of higher education almost entirely require adjustment, namely consisting of lectures, practice, laboratory research, field research, community service, new student admissions, seminars, trial examinations, mid and final semester exams, fieldwork lectures, fieldwork practices, coassistant, and foreign language certification.

Mulawarman University, as a part of higher education, certainly does not remain silent in responding to this dangerous pandemic. Anticipatory actions that have been taken by Mulawarman University begin with the notice dated 2 March 2020, regarding the prohibition of travel to countries experiencing a pandemic and restrictions on official travel to areas with local transmissions (5). Furthermore, Mulawarman University has issued at least five notices to prevent the spread of COVID-19 while ensuring that academic activities can still be carried out. This paper aims to convey most of the efforts to transform higher education policy and academic activities from Mulawarman University in responding to the COVID-19 pandemic.

Legal basis for implementing the transformation of higher education policy and academic activities at Mulawarman University during the COVID-19 pandemic

A. Undang-Undang (UU) No. 24 of 2007, concerns Disaster Management in article 7 paragraph (2).

B. Peraturan Pemerintah (PP) No. 21 of 2020 concerning Large-Scale Civil Restriction.

C. Keputusan Presiden (Keppres) No. 7 of 2020 concerning Task Force for the Acceleration of Handling Corona Virus Disease 2019 (COVID-19).

D. Decree of Head of the National Disaster Management Agency No. 9A of 2020 concerning Determination of the Status of Certain Disaster Emergency Conditions for Coronavirus Outbreaks in Indonesia.

E. Decree of the Head of the National Disaster Management Agency No. 13A of 2020 concerning the Extension of the Status of Certain Disaster Emergencies Outbreaks of Coronavirus in Indonesia.

F. Decree of Governor of East Kalimantan No. 360/K.246/220 concerning Determination of the Status of Extraordinary Events with Certain Emergency Status Conditions due to Coronavirus Disease 2019 in East Kalimantan. 
G. Notice of Rector of Mulawarman University No. 1157/UN17/TU/2020 concerning Increasing the Status of Alertness to the Spread of Coronavirus Disease (COVID-19) through Limitation of Activities in the Campus of the Mulawarman University.

$\mathrm{H}$. Protocol for the Implementation of Academic Activities to Prevent the Spread of Coronavirus Disease (COVID-19) in the Mulawarman University No. 1096/UN17/PP/2020.

\section{Transformation of academic activities for responding to the COVID-19 pandemic}

Based on the Notice of Rector of Mulawarman University No. 1157/UN17/TU/2020, the transformation of Mulawarman University academic activities consists of: (A) Lecture/teaching activities, (B) Practice activities (laboratory and fieldwork practices, (C) Learning evaluation activities (mid and final semester exam), (D) Final project guidance activities, (E) Research and community service activities, (F) Other (related) academic activities, (G) National/international events and professional/service trips at home/abroad, (H) New student admissions activities year of 2020 (SNMPTN; SBMPTN; and SMMPTN), and (I) Student activities/student work units (6).

\section{A. Lecture/teaching activities}

\section{a. Online lectures (online learning system)}

Option 1. The lecturers use the online lecture method as a substitute for face-to-face classes using MOLS (Mulawarman Online Learning System), Google Classroom, Webex, and Zoom. This option needs full support from the information and communication technologies (ICT) unit to provide a good internet/wifi network in the campus area.

Option 2. The lecturers provide material in soft copy form through the head of the class for the later explanation in the form of limited face-to-face (student tutor) or virtual media. Lecturers must have appropriate teaching materials with his duties in the team or, indeed, was prepared teaching materials for the whole semester.

Option 3. The lecturers do electronic tutorials, asynchronously (video), using various ICT or e-learning features, such as MOLS, chat (Whatsapp or Telegram), email, blog, or through social media (Facebook, Instagram, or Twitter). It is suggested to be implemented through campus, although it can also be done with the internet/wifi network's availability (7).

Specifically, the use of MOLS should be encouraged. Learning materials are arranged sequentially and structured in MOLS, to enable students to achieve learning outcomes in stages according to their learning style and speed. The evaluation of the learning process is designed according to the assessment system in online learning. Exam questions can be collected through faculties or departments submitted to the mid and final semester exam team. The exam 
system can be managed centrally by the semester examination team with online exam mechanisms.

Attendance can be online with a screenshot of attendance, assignments for each meeting, or manually (come to campus for attendance) according to the agreement between lecturers and students. Whichever form of teaching and learning is selected is requested, still asked to do attendance (in an agreed manner) for the need for an evaluation. Lecture time follows the existing lecture schedule or can be more flexible (asynchronous) by prioritizing the course learning outcomes' achievement. Flexibility is defined according to time agreed between lecturers and students (8).

\section{b. Student-centered learning system}

They are learning with assistance. The lecturer delivers a hard copy of teaching materials and several references supporting the students' learning process. The lecturer underlines the courses' descriptions and course learning outcomes by the course contract that has been made so that students can increase their self-taught knowledge from other sources (9).

Lecturers can distribute critical questions related to the material provided for monitoring and evaluating the achievement of course learning outcomes. Students give responses and are required to upload answers. Lecturers can use audio-conferencing or chat to carry out discussions or questions and answers. Discussions between lecturers and students can be held online with the available options.

Independent learning in the network (online) enables students to follow the learning process delivered through the network, either individually or in groups. For example, students get study materials in digital form (PDF, DOC, and PPT), do assignments over the network, receive and collect assignments via the network, mailing lists, chat, and other communication media.

Independent learning outside the network (offline) is when the students follow the learning process delivered without using the network. For example, students learn to study learning materials in the form of printed media at home/at work, study material in the form of a video saved on DVD format, and play on a DVD player at home.

Synchronous individual/group learning, where students follow the learning process based on the lecturer's material and information at the same time. For example, students discussing teaching/library materials by chatting or audio or video conference either among group members or with a lecturer. The participation and frequency of implementation are conveyed to the lecturers (10).

Asynchronous individual/group learning, where students follow the learning process in groups via the internet but at different times with delayed 
feedback. For example, students discuss something in groups via email, bulletin boards, discussion forums found on MOLS. The participation and frequency of implementation are conveyed to the lecturers (11).

All study materials must be accessible, cheap, and useful for students to take the exam. Access is either in hard or soft file form. Lecturers must consider students' abilities in getting internet access to avoid students gathering in certain places. Not all residences have internet access, and based on experience, in the end, many students come back together on campus. Lecturers must consider the weight of the material according to the weight of courses, especially for courses that are handled as a team of lecturers. Students use internet access in a home or dormitory to avoid crowds of people (students are in health condition). Attendance and course time, as stated in the online learning system.

\section{B. Practice activities (laboratory and fieldwork practices)}

\section{a. Laboratory practices}

Laboratory practice implementation can be postponed until early June 2020 or take advantage of the holiday period between July and August 2020. If a laboratory practice is held in March, April, and May 2020, the practice must be performed in minimalist participants. The number of students includes only ten people; individually, students report activity, research documents, and reports. Faculties/departments identify laboratory practice needs that cannot be postponed. Laboratory practice activities (groups and individuals) can be carried out by utilizing virtual laboratory applications, including implementing practice exams (if possible). The logical consequence of this need is that the faculty or university's required facilities and infrastructures are provided (12).

\section{b. Field practices}

Same as laboratory practices. All forms of field practices involving large numbers of people, rearrange the schedule by observing developments or canceling them. Field practice activities involving a small number of people (15 people) can be carried out by ensuring that these practices, according to health protocols, prevent COVID-19 transmission. Faculties are expected to communicate intensively with site managers, as well as to know the situation and conditions in which field practice will be carried out.

\section{c. Clinical practices}

Same as laboratory practices. Clinical practices that have not been running have to be rescheduled or postponed. Faculties are expected to communicate intensively with site managers, as well as to know the situation and conditions in which field practice will be carried out. Clinical practices that are currently 
running must follow the procedures for preventing the transmission of COVID19 , which are regulated by each place. Faculties are expected to communicate intensively with site managers, as well as to know the situation and conditions in which field practice will be carried out.

\section{d. Workshop practices}

Same as laboratory practices. Workshop practices can be carried out by limiting the number of people involved in the workshop (a maximum of 15 people) and applying the principle of physical distancing (a minimum distance of 1 meter between people) and using PPE (personal protection equipment). Space capacity is not a measure of practical activity implementation, but rather the number of students participating in the practice. Workshop practices can be carried out by utilizing virtual laboratory applications, including implementing practice exams (if possible). Faculties/departments are asked to identify the character of practical activities and the available facilities and infrastructures. Faculties can rearrange the number of meetings and practical activity materials to minimize the number of meetings (13).

\section{Learning evaluation activities (mid and final exams)}

\section{a. Mid exams}

The mid exam is done by a take-home test/online exam, or other online methods. Schedule an examination mechanism according to the rules of each faculty. The exam is conducted online. Exam questions are collected through the department (depending on each faculty) to be submitted to the examination team. The exam team can centrally manage the online exam system with an online exam mechanism.

\section{b. Final exams}

Final exams will be carried out according to the mechanism and schedule of the academic calendar. The exam is conducted online. Exam questions are collected through the department (depending on each faculty) to be submitted to the examination team. The exam team can centrally manage the online exam system with an online exam mechanism. All course materials to be tested (both mid and final) must be accessible easily, cheaply, and virtually by students participating in the courses who will take the exam-whether accessed online or hard copy or soft copy. Lecturers are obliged to consider students' ability to get internet access to avoid gathering students in certain places. Not all houses, dormitories, and other places of residence have internet access. Experience shows that the campus is a gathering place to get internet access. Lecturers must consider the material according to the course and learning outcomes, especially for the teaching team's courses. Students use 
internet access in a home or dormitory to avoid crowds of people (students are in health condition) (14).

\section{Final project guidance activities}

\section{a. Thesis/dissertation consultation}

It prioritized online guidance. Email proof of guidance can be a screenshot and entered in the guiding logbook or other reporting files. Consultation for the progress of thesis and dissertation research with an online mechanism. Communication using email, chat, or other applications. If it is indispensable, it can be done face to face on campus, provided that students \& lecturers are in good health, and there is an agreement between them. To avoid direct contact, use appropriate PPE, and perform physical distancing. If face-to-face consultation is required, the intensity of the meeting should be shortened. Offline communication can take advantage of lecturer lockers in each faculty, especially for faculties that already have lockers for each of their lecturers.

\section{b. Proposal/research result seminar for students}

Proposal and research results seminar (for theses, dissertations, and other final assignments) are held according to the requirements made at the faculty level. Supervisors and examiners should only attend the seminar's conditions without an audience, or if it is considered necessary, a maximum of 7 (seven) people for the proposal seminar and a maximum of 5 (five) people for the result seminar, especially students who have parallel research. The faculty regulates the technical implementation, including room layout and seating settings, to ensure a minimum distance of 1 meter between participants. Proposal seminars, results, and final examinations can be conducted face-toface. However, the supervisor, examiner, and students should be in good health. Especially for students who will end their study period (in June 2020), during the COVID-19 pandemic, it is regulated by relieving the seminar obligation to only one activity.

\section{c. Undergraduate thesis examination}

Keep doing as usual. Undergraduate thesis exams are carried out by only involving supervisors, examiners, and students. Health protocols must be implemented. Students register for the undergraduate thesis examination following the stages that have been applied. The faculty regulate the implementation technique (layout and physical distancing). According to the agreement, exams are still being carried out, and lecturers who cannot attend due to illness or undergoing isolation may take the exam via chat and telephone. If on the agreed date, but one of the supervisors or examiners 
cannot attend and cannot do it online, then the exam will still be continued accompanied by the head of the department.

\section{d. Thesis examination}

Continue as usual. They are attended by supervisors and examiners, applying health protocols. The number of participants should be arranged as little as possible for faculties using a parallel system. According to the agreement, exams are still being carried out, and lecturers who cannot attend due to illness or undergoing isolation may take the exam via chat and telephone. If on the agreed date, but one of the supervisors or examiners cannot attend and cannot do it online, then the exam will still be continued accompanied by the head of the department. Primarily for master program students whose study period will end in June 2020, requirements such as writing scientific articles and TOEFL certification can be postponed until before graduation if used for final exam requirements (15).

\section{e. Dissertation examination}

Proposal and closed exams are still carried out as usual. Apart from the open examination, the implementation is kept to a minimum, involving only the promoter team, examiners, and the audience. Students register for the exam following the existing rules. The department regulates the technical implementation (layout and physical distancing) with faculty coordination. Supervisors and examiners attend the exam by applying health protocols. The number of participants is set as little as possible for faculties using a parallel system.

The open dissertation examination can still be carried out with some modifications. Another option is that the exam is carried out without an audience. If it is not possible, the open examination is rescheduled so that it is carried out to a minimum by presenting a minimal number of promoters, external and internal examiners. Suppose there are family members who wish to attend the free exam. The audience is limited to their immediate family, namely parents, husband, wife, and children. However, they are not in the room during the exam but are waiting outside.

According to the agreement, exams are still being carried out, and lecturers who cannot attend due to illness or undergoing isolation may take the exam via chat and telephone. If on the agreed date, but one of the supervisors or examiners cannot attend and cannot do it online, then the exam will still be continued accompanied by the head of the department. Especially for doctoral program students whose study period will end in June 2020, requirements such as writing scientific articles and TOEFL certification can be postponed until before graduation if used for final exam requirements. 


\section{E. Research and community service activities}

\section{a. Laboratory research (individual or group)}

Research involving many people, such as sensory testing, focus group discussions, dissemination, seminars, is postponed or involves fewer respondents using different data collection methods. This applies to both lecturer and student research to always use the appropriate personal protective equipment (i.e., masks and gloves). The laboratory sets the COVID19 prevention rules.

The students report in writing (via chat/email) to the head of the laboratory, faculty, or research and community service institute (according to the funding scheme) about the laboratory used, the type of analysis, the analysis period, and the names of the teams involved for data collection. Researchers fill out a laboratory attendance book for tracing purposes. All laboratories are required to prepare standard operating procedures for laboratory use. Wherever possible research is not overtime. Suppose the research cannot be avoided for overtime. In that case, it is requested to apply for permission in writing (via chat/email) to the laboratory's head. Especially those that should be carried out at night, if possible, temporarily avoided.

The laboratory head regularly reports (via chat/email) the list of laboratory users to the department and faculty. In the conditions of the COVID-19 pandemic, more intensive monitoring of laboratory use is needed. Ensure health insurance is active for all team members involved or can request the required medical certificates. Suppose there is an incident (work accident/illness). In that case, the laboratory assistant will immediately provide a written notification (via chat/email) to the laboratory's head as per existing standard operational procedures (16).

\section{b. Field research (individual or group)}

Research involving many people, such as focus group discussions, is postponed or involves fewer respondents using different data collection methods. If the research is carried out in a village or work area of an institution, it is necessary to ascertain whether the destination location can accept a research team and has regulations related to COVID-19. Always use appropriate personal protective equipment (PPE) (i.e., masks, gloves) during researchers' activities.

The report in writing (via chat/email) to faculty or research and community service institutions (according to the funding scheme) regarding the locations visited, the needs, the visit period, and the names of the teams involved, for monitoring and evaluation of laboratory activities throughout the COVID-19 pandemic. Ensuring health insurance is active for all team members involved, provided by the researcher. If it is unavoidable to visit an area where there is a 
massive spread of COVID-19, it is expected to report it to the local Health Office. Whenever possible, it should be moved according to the specified research location criteria. Suppose there is an incident (work accident/illness). In that case, the team leader will immediately provide a written report via chat/email to the faculty or research and community-service institution according to the situation that occurs, especially those related to the symptoms of COVID-19 (17).

\section{c. Community service program (KKN)}

Preparations for the Community Service Program (KKN) are still carried out by online communication with frequent meetings once a week. Especially for the KKN, which is managed by the Mulawarman University Institute for Research and Community Service. If until July and August 2020 pandemic continues, the form of the KKN will be adjusted with communication to the local government, for several options, including:

Option 1: KKN is shortened to two weeks; part of the community service process can be converted into online activities (such as data collection interviews and online teaching), jointly defined with the local government. It is hoped that the model to be carried out will provide implementation guidelines based on communication with local governments.

Option 2: Equalizing KKN is done by social/engineering experimentation, which is uploaded in the form of a video or website with conditions that will be determined later. It is hoped that the model to be carried out will provide implementation guidelines based on communication with local governments.

If the faculty has other students' social service activity models that allow it to be equalized, it can communicate with the research and communityservice institution. Whatever the KKN model is implemented, it is essential to ensure that health insurance is active for all team members involved. If necessary, a medical certificate can be requested, stating that they can participate in KKN by considering the COVID-19 pandemic situation. Suppose there is an incident (work accident/illness). In that case, the team leader will immediately provide a written report via chat/email to the faculty or research and community-service institution according to the situation that occurs, especially those related to the symptoms of COVID-19 (18).

\section{F. Other (related) academic activities}

\section{a. Judiciary and graduation}

The judiciary was postponed or rescheduled while still granting rights to students (i.e., transcripts, graduation certificates). Especially for students who have registered for graduation, the judiciary can be carried out at a minimum the principle of physical distancing. For example, the judiciary is carried out 
briefly, gradually (per small group), and in rotation (entering the room one by one) to receive transcripts and graduation certificates.

Graduation is postponed or rescheduled while still granting rights to students (i.e., transcripts, graduation certificates). After the planned graduation date (28 March 2020), a copy of the certificate can be printed out by the graduate or faculty. The faculty can legalize a copy of the certificate. If the COVID-19 pandemic continues until two waves of graduation cannot be carried out, it is considered that the original diploma will be given to graduates without graduation.

\section{b. Libraries (borrowing, reading, and other library administration)}

During the COVID-19 pandemic, libraries are closed for direct services (except for student loan-free verification as a requirement for exams/graduation), but libraries are open for online services. Some of the services that can be provided include openly published catalogs (selfextension), e-book services, and e-journal services. Employees' activities while the library is closed will follow directions from the university. If employees come to work, activities that can be carried out are digital publications (managing websites, email, and social media) and stock taking of book/article collections (19).

\section{c. Language center (training and TOEFL test)}

All training activities and regular courses are temporarily closed until further notice. The language center follows the policies of the university. Private course activities will continue as long as there is an agreement between the two parties, namely the participants and the instructor. If agreed, it will be carried out according to health protocols. Registration for the TOEFL test will be temporarily closed until further notice. Students who are about to graduate in June 2020 and have not passed the TOEFL can register manually at the language center by showing a completion certificate and will be given a particular test for this group (20).

\section{G. National/international events and professional/service trips at home/abroad}

For national and international seminars/workshops/conferences/public lectures, and domestic/foreign official travel. All academic trips abroad and to Indonesia's affected areas are postponed and follow the latest developments from the authorities. If it is a collaborative activity, always communicate with partners to be rescheduled or find a solution for the situation. Visits of colleagues from affected countries and areas are expected to be postponed or rescheduled. There needs to be intense communication with colleagues regarding delays/reschedules if it cannot be postponed or rescheduled then canceled. 
The report in letter (via chat/email) to faculties and research and community service institutions (according to the funding scheme) by copying to the university the location visited, the needs, the period of visit, and the name of the team involved (specifically for activities that use the program scheme of the ministry). Funded scientific activities, independent or other funding sources, must communicate according to the established protocol. Suppose participants are already at the event's location. In that case, they are asked to return immediately, except for activities that are urgently needed in the destination region/country, with due observance of the rules applies. If it is unavoidable to visit areas where there is a massive spread of COVID-19, it is expected to report to the Health Office (21).

\section{H. New student admissions activities year of 2020 (SNMPTN; SBMPTN; and SMMPTN)}

a. National selection and joint selection to enter state university (SN-SBMPTN) 2020

The SN-SBMPTN implementation method awaits the results of coordination with the university entrance test institution (LTMPT) related to the computer-based test examination policy, file submission and verification, and quarantine for participants/committees who are suspects of COVID-19. SN-SBMPTN is a program managed by LTMPT and implemented by the organizing university accordingly. If a computer-based test is carried out, the committee wears the appropriate PPE (gloves, long-sleeved clothes, closed shoes, gloves, and masks) during the test process, registration, and file verification (22).

1. Hand sanitizers are available at the registration, verification, and test committee desks.

2. The committee prepared a separate examination room for participants who were sick.

3. The room was sprayed with disinfectant before and after the test (every day).

4. Participants have their body temperature checked using an infrared thermometer.

5. Participants who have a body temperature of $\geq 38 \mathrm{C}$ will not be allowed to enter the standard exam room (separate exam room).

6. Masks will be given to participants who are sick (cough/cold).

7. Quarantine participants/committees who become suspects of COVID-19 are carried out in collaboration with the Health Office.

\section{b. Independent selection to enter state university year of 2020 (SMMPTN)}

The SMMPTN implementation method awaits the results of coordination with the university entrance selection team regarding the computer-based test exam policy, file submission, and verification, and quarantine protocol for 
participants/committees who are suspects. The commencement of SNSBMPTN is in waiting for the development of COVID-19 in Indonesia and East Kalimantan. If implemented by a computer-based test exam, the committee wears the appropriate PPE (gloves, long sleeve clothes, closed shoes, gloves, and masks) during the test process, registration, and file verification. Follow health protocols that have been ruled (idem ditto SN-SBMPTN) - taking into account the grades that have been available on the previous selection test. If necessary, the SMMPTN committee will develop an online local registration and selection system for reducing direct contact with participants.

\section{c. New student parents meeting the year of 2020 (POMB)}

POMB implementation will be evaluated because of developments in the situation, both at the university and faculty level. If POMB can be carried out, the meeting is limited to inviting student-parent representatives or other methods. Furthermore, the results are submitted online. If conditions do not allow, the POMB year of 2020 canceled.

\section{d. Introduction to campus life for new students year of 2020 (PKKMB)}

Implementation will be carried out to see the development of the COVID19 pandemic and policies from the ministry. PKKMB is a national program.

\section{Student activities/work units}

Student activities that are in line with ministry activities are organized internally and carried out online. If it is not possible online, then it will be postponed. According to ministerial regulations, the activities of student organizations (DPM KM, BEM KM, and UKM), Mulawarman University have been temporarily suspended. The activities of the student services staff follow university directions.

\section{Handling for students who have ended the study period}

With various obstacles in academic services at Mulawarman University during the COVID19 pandemic, as well as the issuance of ministerial regulations regarding the learning period for implementing educational programs, Mulawarman University responded with the following policies:

1. An extension is given for students who cannot complete their studies due to the COVID-19 pandemic. The extension of time applies only to undergraduate students of class 2013, master program students of class 2016, and doctoral students of class 2013. As for diploma and professional programs, the additional time for completing the study refers to the faculty regulations. The additional study completion time will not change the maximum study period for each study level, as stipulated in the ministerial regulation. According to the ministerial regulations, this means that the 
maximum study period will be printed on the certificate and transcript of the graduates who receive an extension of study time.

2. To follow up on point 1 above, and to consider that the students are currently in their hometowns, the faculty are asked to collect data as soon as possible collectively for students. Studies that meet the requirements so that they can be processed immediately.

3. For all students who are about to expire their study period, if all graduation requirements have been met (such as the TOEFL test and journal articles) and in consideration of their supervisor or promoter, it is possible to carry out final examination activities, then asked the faculty to hold them online without reducing the quality of the process and the results. This online procedure is based on the consideration of the timely completion of the study.

4. Considering that the consequences of the COVID-19 pandemic have made some laboratory and field practice activities unable to be carried out, and considering that graduates' competence through the practice cannot be equalized in other forms of activity, it is requested to be rescheduled by considering the situation. The implementation time option is between July and August 2020 or July and December 2020.

5. Suppose the practice activity is used as a requirement for the final semester examination, it is requested that the final semester examination can be scheduled when the practice is completed. Input student scores will be reopened for these late activities. As for other courses that do not require practice, as long as students have obtained all course material that must be delivered, and there is an opportunity for participant discussion, it is expected that they no longer impose minimum attendance requirements. In this case, the final semester exams are still carried out by the predetermined implementation time. Assure lecturers and students, the final semester exams are held online. Faculties are asked to prepare technically and their schedule.

6. The necessity of conducting lectures (or other academic activities) online for all courses is an inevitable condition. However, the situation has made a burden on the cost of purchasing pulses, both for lecturers and especially students. Meanwhile, the university and faculty are still trying to find a solution that can be accounted for by financial regulations, for the possibility of providing credit subsidies. For this reason, each lecturer is asked to be wise in the approach to delivering the material that must be given, among others, by varying online lectures during the completion of the remaining semesters. Perhaps it can be done by distributing material through, for example, chat/email first, then online system learning is carried out for discussion or question and answer material that has been distributed to students. The lecture schedule remains by the schedule made by the institution unless there is an agreement with students. This is important to avoid overlapping course schedules or internet access that can be obtained by students. 
7. This final project research during the COVID-19 pandemic also needs to be addressed by supervisors or promoters. If the condition is urgent, and it is challenging to implement so that it can be modified or even completely changed. For those who have already conducted proposal seminars, there are two alternatives: (1) For research proposals that are only slightly modified/do not change the substance of the topic, there is no need to conduct a re-proposal seminar (but need notification to the examining team); or (2) For research proposals that have changed completely, it is necessary to re-seminar with the entire team of examiners online to obtain input (without changing or possibly improving the assessment of the seminars that have been carried out).

8. Especially for the implementation of the TOEFL test, which is one of the requirements for student graduation and the implementation of community service program (KKN), during this emergency period, an equalized replacement system (online program) has been developed, both by the language center and research and community service institutions as the person in charge of each program. Faculties were instructed to coordinate with their students, who were about to finish their studies to contact the two institutions.

9. Especially for students whose study period must end, but due to an emergency, they have to take an extension of the study completion time for a maximum of 1 semester, so they are no longer subject to tuition fees.

\section{Conclusion}

The academic transformation taken by Mulawarman University in responding to the COVID-19 pandemic is massive and comprehensive regarding aspects of lectures, practice, laboratory and field research, community service, new student admissions, seminars, trial examinations, mid and final exam semesters, community work program, fieldwork practices, co-assistants, and foreign language certification. Of course, other studies regarding the economic, social, and humanitarian impacts during the period of social distancing as a result of the COVID-19 pandemic on the academic community need to be studied and anticipated by Mulawarman University.

\section{REFERENCES}

1. Li LQ, Huang T, Wang YQ, Wang ZP, Liang Y, Huang TB, et al. COVID-19 patients' clinical characteristics, discharge rate, and fatality rate of meta-analysis. J Med Virol. 2020;92(6):577-83.

2. Worldometer. COVID-19 Coronavirus Pandemic. Worldometer. 2020.

3. Paramita S, Rahmadi A, Isnuwardana R, Nugroho RA. One-month Progress of COVID-19 Cases in East Kalimantan, Indonesia. Open Access Maced J Med Sci. 2020;8(T1):45-50.

4. Djalante R, Lassa J, Setiamarga D, Mahfud C, Sudjatma A, Indrawan M, et al. Review and analysis of current responses to COVID-19 in Indonesia: Period of January to March 2020. Prog Disaster Sci. 2020;100091. 
5. Ministry of Health Republic of Indonesia. COVID-19. Infeksi Emerging. 2020.

6. Universitas Mulawarman. Universitas Mulawarman. Satgas COVID-19 Universitas Mulawarman. 2020.

7. Dhawan S. Online learning: A panacea in the time of COVID-19 crisis. J Educ Technol Syst. 2020;49(1):5-22.

8. Rapanta C, Botturi L, Goodyear P, Guàrdia L, Koole M. Online university teaching during and after the Covid-19 crisis: Refocusing teacher presence and learning activity. Postdigital Sci Educ. 2020;1-23.

9. Kaput K. Evidence for Student-Centered Learning. Educ Evol. 2018;

10. Watts L. Synchronous and asynchronous communication in distance learning: A review of the literature. Q Rev Distance Educ. 2016;17(1):23.

11. Wu D, Bieber M, Hiltz SR. Engaging students with constructivist participatory examinations in asynchronous learning networks. J Inf Syst Educ. 2019;19(3):9.

12. Lau CS, Kamaludin NA, Aw TC. Laboratory practice in the face of Covid-19. Proc Singapore Healthc. 2020;2010105820952486.

13. Gal L, Israel-Fishelson R. Enhancing Students Virtual Engagement Using Asynchronous Workshop: COVID-19 Case Study. EdMedia+Innov Learn. 2020;31-6.

14. George ML. Effective Teaching and Examination Strategies for Undergraduate Learning During COVID-19 School Restrictions. J Educ Technol Syst. 2020;49(1):23-48.

15. Bal IA, Arslan O, Budhrani K, Mao Z, Novak K, Muljana PS. The Balance of Roles: Graduate Student Perspectives during the COVID-19 Pandemic. TechTrends. 2020;1-3.

16. Omary MB, Eswaraka J, Kimball SD, Moghe P V., Panettieri RA, Scotto KW. The COVID19 pandemic and research shutdown: staying safe and productive. J Clin Invest. 2020;130(6).

17. Dodds S, Hess AC. Adapting research methodology during COVID-19: lessons for transformative service research. J Serv Manag. 2020;

18. Heo S-E. Convergence study on major satisfaction and academic achievement depending on the characteristics of community service experience in university students. J Korea Converg Soc. 2016;7(4):85-96.

19. Ali MY, Gatiti P. The COVID-19 (Coronavirus) pandemic: reflections on the roles of librarians and information professionals. Heal Inf Libr J. 2020;37(2):158-62.

20. Ross AF, DiSalvo ML. Negotiating displacement, regaining community: The Harvard Language Center's response to the COVID-19 crisis. Foreign Lang Ann. 2020;

21. Chinazzi M, Davis JT, Ajelli M, Gioannini C, Litvinova M, Merler S, et al. The effect of travel restrictions on the spread of the 2019 novel coronavirus (COVID-19) outbreak. Science (80- ). 2020;368(6489):395-400.

22. World Health Organization. Protocol for assessment of potential risk factors for coronavirus disease 2019 (COVID-19) among health workers in a health care setting. World Heal Organ. 2020;23 March. 